\title{
Prevalence and causes of communication disorders- A retrospective study from northern Karnataka
}

\author{
Pottackal Mathai Jijo $^{\mathrm{a}}$, Konadath Sreeraj ${ }^{\mathrm{b}}$, K. Sandhya ${ }^{\mathrm{a}, *}$, M. Preethi ${ }^{\mathrm{b}}$, Pujar Rashmi ${ }^{\mathrm{c}}$ \\ a JSS Institute of Speech and Hearing, Near tapovana, kelageri, Dharwad, 580007, India \\ ${ }^{\mathrm{b}}$ All India Institute of Speech and Hearing, Manasagangothri, Mysuru, 570006, India \\ ${ }^{\mathrm{c}}$ Karnatak University, Dharwad, 580003, India
}

\section{A R T I C L E I N F O}

\section{Keywords:}

Prevalence

Communication disorder

Risk factors

Hearing impairment

North Karnataka

\begin{abstract}
A B S T R A C T
Introduction: Communication disorders affect an individual's social, emotional, cognitive and behavioral wellbeing. Estimating the prevalence rate and cause of communication disorders can assist in prevention, early identification, intervention, rehabilitation and counselling.

Method: A Retrospective study was carried out by reviewing the clinical records of clients who visited JSS Institute of Speech and Hearing, Dharwad for last three years. Additionally, data of clients who attended free speech and hearing camp conducted at Bijapur was collected. A total of 2064 clients who were diagnosed as having communication disorders were included for the study.

Result: It was found that among the clients diagnosed as having communication disorders, Hearing Impairment was found to be the most prevalent in both children $(30.81 \%)$ and adults $(32.1 \%)$. Further, specific language impairment (8.04\%), Delayed Speech and Language secondary to Cerebral palsy (7.21\%) and delayed speech and language secondary to Intellectual Disability (6.15\%) were also a few of the communication disorders seen. Among the risk factors causing communication disorders, consanguineous marriage (20.78\%) was found to be the prominent causative factor followed by positive family history of speech and language disorder (7.12\%), delayed birth cry $(7.07 \%)$ and neonatal seizure $(5.86 \%)$ etc.

Conclusion: The results of the present study revealed that communication disorders are highly prevalent in northern part of Karnataka. Hearing impairment was one of the most commonly seen conditions in both pediatric and adult population. History of parental consanguinity was noted in a large number of children with communication disorders.
\end{abstract}

\section{Introduction}

Communication refers to sending and receiving of messages, information, ideas or feelings. ${ }^{1}$ Communication will be effective when speech, language and hearing processes work efficiently. Disruption of any one among these processes can lead to a communication disorder. Hearing impairment, intellectual disability, structural and functional deformities in speech production system are a few conditions that may lead to communication disorders. Studies have identified various risk factors that are leading to communication disorders namely low birth weight, premature birth, neonatal jaundice ${ }^{2}$ post natal infection, consanguinity ${ }^{3}$ delayed birth cry, birth asphyxia, neonatal seizure ${ }^{4}$ syndrome, craniofacial anomalies ${ }^{5}$ positive family history. ${ }^{6,7}$ Over the decades, various researchers across the world have studied the incidence and prevalence of communication disorders. Studies have been conducted to estimate the rate of communication disorders in children as well as adults. According to census of India $2011^{8}$ the proportion of hearing disability was found to be $18.9 \%$, speech disability was $7.5 \%$ and mental retardation was 5.6\%. Shanbal JC \& Reddy MS (2015) ${ }^{9}$ Studied prevalence of communication disorders in a total number of 2010 children. As per the results a total of $11.5 \%$ of children exhibited communication disorders. Among them, distribution of language disorder was $7.4 \%$, speech disorder $3.8 \%$ and multiple disorders was $0.2 \%$. Another, survey based study by Kondath $S$ et al. (2013) ${ }^{10}$ revealed $6.07 \%$ of participants to have communication disorders and found greater number $(90.58 \%)$ of auditory disorders compared to speech and language disorders $(9.42 \%)$. Similarly, a study done by Sinha $S$ et al. $(2017)^{11}$ also found high prevalence of auditory disorder (3.30\%) compare to speech and language disorders (0.7\%). Devadiga D,Varghesh AL \& Bhat $\mathrm{J}(2014)^{12}$ analyzed hospital based retrospective data

\footnotetext{
* Corresponding author.

E-mail addresses: jijoaudio@gmail.com (P.M. Jijo), sreerajkondath@aiishmys.in (K. Sreeraj), gangollibhoomi@gmail.com (K. Sandhya), preethimallesha@gmail.com (M. Preethi), rashmi.badiger138@gmail.com (P. Rashmi).
} 
of one year which showed high prevalence of auditory disorder (62\%) followed by language disorders (24\%) and speech disorders (14\%) respectively. Further, they observed prevalence of communication disorders was high in males compared to females.

It is evident from the above literature that there are only a few studies done in India that investigated the prevalence of communication disorders. As a country of world's second largest population having huge diversity in economy, geography and culture there is a need to estimate the prevalence and causes of communication disorders in various parts of India. Though a few prevalence studies have been conducted in southern part of Karnataka, no such investigations have been done in northern part of Karnataka. It is possible that higher prevalence of communication disorders might be seen in northern Karnataka where literacy and economic status are lower than southern states of Karnataka. Hence, this study aims at estimating the prevalence and causes of communication disorders in northern Karnataka.

\section{Method}

\subsection{Participants}

This retrospective study was carried out by reviewing the clinical records of clients who visited JSS Institute of Speech and Hearing, Dharwad, Karnataka between January 2015 and July 2018. Additionally, the data collected from 192 clients who attended free speech and hearing camps conducted at Bijapur, Karnataka in the month of January and June 2018 were also included in the study. During the period under review, a total of 2064 clients who were diagnosed as having communication disorders were included. The diagnosis of all the clients had been carried out by experienced Audiologists and Speech Language Pathologist. The diagnosis included hearing loss, specific language impairment, delayed speech and language secondary to hearing impairment, delayed speech and language secondary to autism spectrum disorder, delayed speech and language secondary to intellectual disability, delayed speech and language secondary to cranio facial anomalies, specific learning disability, fluency disorder, voice disorder and speech sound disorder. Data of those clients visited the clinic with some complaint but found normal after testing were not included in the study.

\subsection{Procedure}

All the participants were tested to identify and diagnose any speech, language and hearing problems. In order to diagnose speech and language disorders, standard test materials such as REELS (Receptive Emergent Expressive Language Scale), RELT (Receptive Expressive Language Test), and 3D-LAT (3 Dimension Language Acquisition Test), SSI (Stuttering Severity Instrument), ERS(Early Reading Skill), WAB (western Aphasic Battery), FDA (Frenchay dysarthria assessment) and for diagnosing voice disorders, calibrated Dr.Speech and Vagmi module had been used.

Similarly, for diagnosing adult cases with hearing loss, pure-tone thresholds had been obtained using calibrated diagnostic audiometers (Interacoustics AD-629 or ALPS AD 2000). For pediatric case with hearing loss, Transient Evoked Oto acoustic emissions were recorded using Otodynamics ILO 292. ABR had been recorded using a two channel Auditory Evoked Potential (Interacoustics Eclipse- 15) system. Middle ear status was evaluated using a calibrated immittance meter (Interacoustic AT-235). Clients having average audiometric threshold at $500,1000,2000 \& 4000 \mathrm{~Hz}$ greater than $26 \mathrm{dBHL}$ were considered as hearing impaired (WHO, 2008) ${ }^{13}$ and were included in the study.

Demographic data, possible etiological factors such as prenatal, perinatal and postnatal histories, family history, consanguinity, other medical history etc. were obtained from each individual. This information was tabulated and analyzed using SPSS software.

\section{Results}

A total of 2110 clients were reported to the clinic. Among them, 2064 cases were diagnosed as having a communication disorder. Males (64.58\%) were found to have a greater percentage when compared to females (35.41\%). Distribution of each communication disorder is mentioned in Fig. 1.

It can be observed in Figure -1 that maximum number of clients had hearing impairment (1299) 62.9\%. Among those with hearing impairment, there were $663(32.1 \%)$ adults with hearing loss and 636 (30.81\%) children having delayed speech and language secondary to hearing loss. There were $166(8.04 \%)$ children had the diagnosis of specific language impairment. Delayed speech and language secondary to cerebral palsy and intellectual disability were found in $149(7.21 \%)$ and $127(6.15 \%)$ children respectively. There were $88(4.26 \%)$ clients with fluency disorder, $79(3.82 \%)$ with speech sound disorder and $49(2.37 \%)$ clients having delayed speech and language secondary to autism spectrum disorder. voice disorder, delayed speech and language secondary to seizure disorder, Syndrome condition were seen in 28 (1.35\%) $28(1.35 \%)$ and $36(1.74 \%)$ clients respectively. Other conditions such as adult language disorder (11) $0.53 \%$, motor speech disorder (9) $0.43 \%$, learning disability (6) $0.29 \%$ delayed speech and language with cranial facial anomalies (5) $0.24 \%$, delayed speech and language secondary to attention deficit hyper active disorder (5) $0.24 \%$ ) were seen in very few clients.

It can be inferred from Table 1 that among 12 risk factors for communication disorders, consanguineous marriage was the highest seen risk factor $429(20.78 \%)$ associated with most of the communication disorders. Relevant family history147 (7.12\%), delayed birth cry $146(7.07 \%)$ and neonatal seizure 121(5.86\%), low birth weight 115 (5.57\%), premature delivery $111(5.37 \%)$ were the next common risk factors. Neonatal jaundice $83(6,27 \%)$, syndrome $36(1.74 \%)$, hypoxia $16(0.77 \%)$, pre $11(0.53 \%)$ and post natal infection $26(1.25 \%)$ and craniofacial anomalies $5(0.29 \%)$ were also some of the contributing factors for causing a communication disorder.

\section{Discussion}

This retrospective study was carried out to determine the prevalence and causes of communication disorders in northern part of Karnataka. The results of the study revealed that prevalence of hearing impairment was the highest among various communication disorders. This shows that hearing impairment was the communication disorder that was reported maximally in this region. This could be due to the symptoms of hearing impairment that are easily identifiable. Moreover, widespread awareness on facilities available for individuals with hearing impairment would have also lead to this. Also, auditory disorders are usually associated with evident signs and symptoms for which medical help is seeked and hence patients tend to report to an audiologist. In contrast, speech and language disorders are less reported due to the lack awareness on professional services available. ${ }^{12}$ The present study findings are in consonance with the study carried out in north Karnataka region (Belgaum) $2014^{14}$ which showed hearing impairment was third highest disability (7.24\%) seen followed by mental disability (5.92\%) and speech disability(95.26\%) and in the region of kaluburgi $(2011)^{15}$ the disability percentage of hearing is about(24.07), speech (5.5\%) and intellectual disability was (6.12\%).Similar findings are also observed in south Karnataka region studies Kondath S et al. (2013) reported in the region of Mandya; Devadagi D,Varghesh AL \& Bhat J (2014) in the region of Mangalore also found high prevalence rate of Audiological and otological disorder followed by speech and language disorders. Similar trend of result also observed in north India region study by Sinha S et al.(2017) reported the prevalence rate of communication disorder in north west region of India(Gujarath) which showed which showed 1187 (4.09\%) of individual found to have communication disorder among them $3.30 \%$ of individual had auditory disorder 


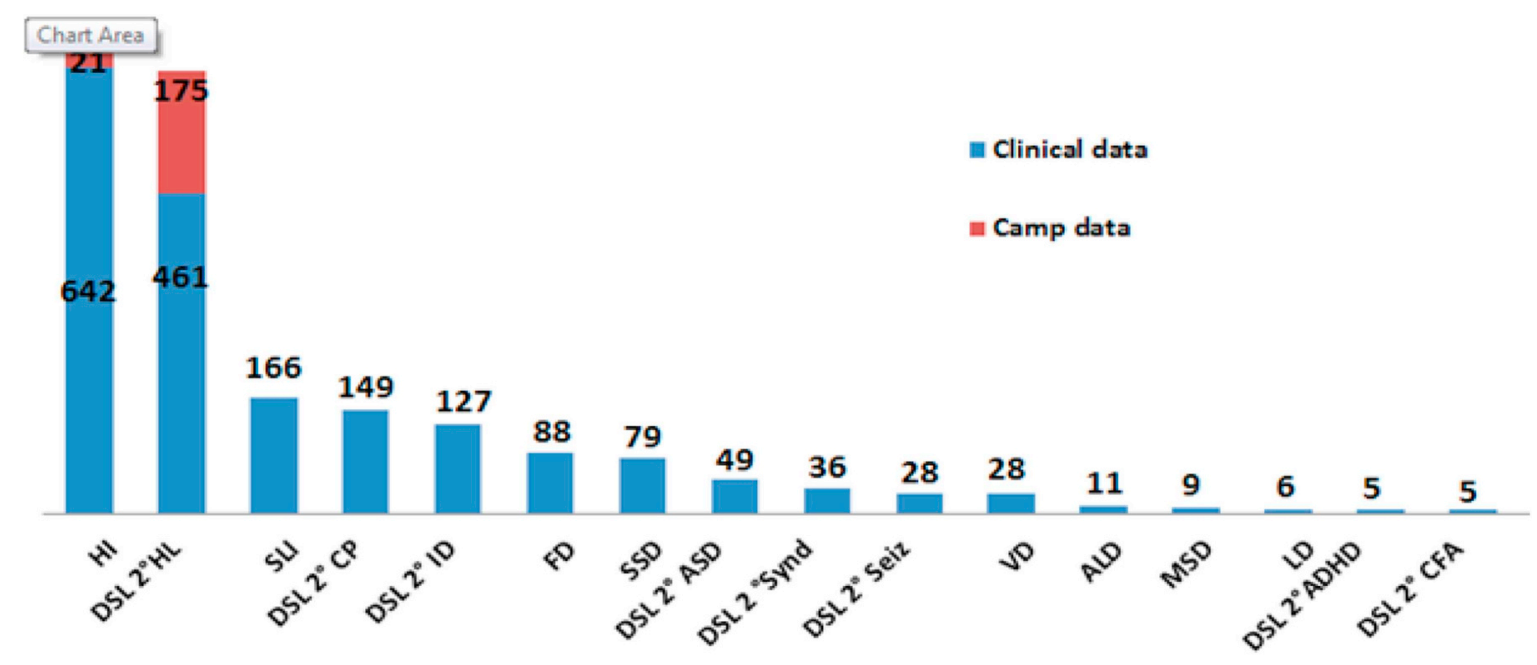

\section{NOTE:}

HI -Hearing impairment

VD-Voice disorder

LD-Learning disability

ALD-Adult language disorder

MSD- Motor speech disorder

SSD-Speech sound disorder

SLI-Specific language impairment
DSL $\mathbf{2}^{\circ} \mathbf{H L}$ - Delayed speech and language secondary to hearing loss

DSL 2 ASD-Delayed speech and language secondary to autism spectrum

DSL $2^{\circ} \mathbf{C P}$ - Delayed speech and language secondary to cerebral palsy

DSL $2^{\circ}$ Synd -Delayed speech and language secondary to Syndrome

DSL2 $^{\circ}$ Seiz- Speech and language secondary to seizure disorder

DSL $^{\circ}$ CFA- Delayed speech and language secondary to cranio facial anomalies

DSL $2^{\circ}$ ADHD- Delayed speech and language secondary to attention deficit hyperactive disorder

Fig. 1. Distribution of various communication disorders.

followed by speech and language disorder(0.79\%).It was found in the current study that communication disorders were seen more in pediatrics population compared to the adults and geriatrics. Delayed speech and language development causing parental concern might have led to the identification of such conditions in children. This is supported by other studies in both south Karnataka and north India.Shanbal JC \& Raddy MS (2015) in the region of Mysore, Karnataka estimated distribution of communication disorder in school age children, $11.5 \%$ of school children were found to have communication disorders. Among them distribution of language disorder was high (7.4\%) followed by

Table 1

Distribution of risk factors across various communication disorders.

\begin{tabular}{|c|c|c|c|c|c|c|c|c|c|c|c|c|}
\hline & DSL $2^{\circ} \mathrm{HI}$ & $\mathrm{DSL}^{\circ} \mathrm{MR}$ & DSL2 ${ }^{\circ} \mathrm{CP}$ & $\mathrm{DSL}^{\circ} \mathrm{SIZ}$ & DSL2 ${ }^{\circ}$ synd & SLI & DSL $2^{\circ}$ ASD & SSD & DSL $2^{\circ}$ ADHD & DSL $2^{\circ}$ CFA & FD & LD \\
\hline Parental Consanguinity & 259 & 47 & 31 & 7 & 5 & 46 & 6 & 16 & 2 & 5 & 4 & 1 \\
\hline Relevant Family history & 78 & 18 & 8 & 3 & 4 & 19 & 5 & 7 & 0 & 0 & 2 & 3 \\
\hline Delayed birth cry & 44 & 21 & 32 & 10 & 7 & 15 & 7 & 4 & 1 & 2 & 2 & 1 \\
\hline Seizures & 10 & 25 & 40 & 21 & 4 & 13 & 5 & 3 & 0 & 0 & 0 & 0 \\
\hline Low birth weight & 60 & 15 & 18 & 1 & 4 & 12 & 1 & 2 & 0 & 0 & 1 & 1 \\
\hline Pre mature delivery & 53 & 11 & 16 & 1 & 4 & 17 & 3 & 5 & 1 & 0 & 0 & 0 \\
\hline Neonatal jaundice & 22 & 11 & 13 & 2 & 6 & 17 & 6 & 5 & 1 & 0 & 0 & 0 \\
\hline Syndrome & 1 & 0 & 0 & 0 & 35 & 0 & 0 & 0 & 0 & 0 & 0 & 0 \\
\hline Post natal infection & 8 & 3 & 5 & 0 & 0 & 3 & 2 & 4 & 0 & 1 & 0 & 0 \\
\hline Hypoxia & 6 & 1 & 6 & 0 & 1 & 0 & 0 & 0 & 1 & 1 & 0 & 0 \\
\hline Pre natal infection & 5 & 0 & 0 & 0 & 1 & 4 & 0 & 0 & 1 & 0 & 0 & 0 \\
\hline CFA & 1 & 0 & 0 & 0 & 0 & 0 & 0 & 0 & 0 & 5 & 0 & 0 \\
\hline
\end{tabular}


speech disorder (3.8\%) and multiple disorder (0.2\%). Parvez A et al. $(2017)^{16}$ also reported prevalence rate of hearing impairment in (Uttar Pradesh, north India) school going children and result showed $17.9 \%$ $(109 / 610)$ reported to have hearing impairment.

Among the risk factors causing communication disorders, consanguinity was found to be the highest. Studies have reported higher number of consanguineous marriages in northern part of Karnataka compared to south. This could be because the tradition of consanguineous marriage is common in northern part of Karnataka compared to its south. Further, there is lack of awareness about risks of having consanguineous marriage in this region of Karnataka. This findings supported by another north Karnataka study in the region of Bagalkot by Patil M et al. (2018) ${ }^{17}$ study was done to know the risk factors leading for hearing impairment. Result showed consanguineous marriage was most common risk factor observed. Bittles $\mathrm{AH}$ $(2002)^{18}$;Zakzour S $(2002)^{19}$;Zakzouk S,Elsayed Y\& Bafaqeah SA $(1993)^{20}$ also reports prevalence of hearing impairment is high in children with history of parental consanguinity.

Premature delivery, neonatal jaundice, low birth weight, seizures, hyperbilirubinemia, pre and post natal infection, asphyxia, are also some of the risk factors leading to communication disorders(Singhi PD, Ray M \& Suri G(2002) $)^{21}$;Sankar C \& Mundkur N(2005) ${ }^{22}$; Gladstone M $(2010)^{23}$;Armatas V $\left.(2009)^{24}\right)$.

\section{Conclusion}

From the current study we can infer that among the communication disorders reported, prevalence rate of hearing impairment was highest followed by speech and language disorder. Further, it was found that communication disorders were highly prevalent in male compared to female in both children and adults.

Further, it was noted that parental consanguinity was the highest found risk factor of communication disorders followed by family history, delayed birth cry, neonatal seizure etc. Hence, the present study is a preliminary attempt to establish region specific prevalence rate and causes of communication disorders. The study also highlight the importance of awareness programs in general public and other professionals about causes, prevention, identification and rehabilitation of communication disorders.

\section{Acknowledgement}

Authors thank Director, All India Institute of Speech and Hearing (AIISH), Mysore for supporting the research through funding and other approvals. The study was funded by AIISH Research Fund, Sanction No. SH/CDN/ARF/4.7/2017-18. Authors acknowledge Director, JSS institute of speech and hearing, Dharwad for permitting to carry out the research. Further, we thank staff and students of JSS institute of speech and hearing for their support during data collection.

\section{Appendix A. Supplementary data}

Supplementary data to this article can be found online at https:// doi.org/10.1016/j.cegh.2019.06.002.

\section{Conflicts of interest}

The authors, whose names are listed in the authorship form, have read the authorship and conflict of interest statement and have no conflict of interest as such. They have potentially compromised by a desire for financial gain, prominence, professional advancement or a successful outcome.

\section{References}

1. Hulit LM, Howard MR. Born to Talk. third ed. Boston: Allyn and Bacon; 2002.

2. Bergman I, Hirsch RP, Fria TJ, Shapiro SM, Holzman I, Painter MJ. Cause of hearing loss in the high-risk premature infant. J Pediatr. 1985 Jan 1;106(1):95-101.

3. Durkin M. The epidemiology of developmental disabilities in low-income countries. Dev. Disabil. Res. Rev. 2002 Jan 1;8(3):206-211.

4. Torfs CP, van den Berg BJ, Oechsli FW, Cummins S. Prenatal and perinatal factors in the etiology of cerebral palsy. J Pediatr. 1990 Apr 1;116(4):615-619.

5. Nagarajan R, Savitha VH, Subramaniyan B. Communication disorders in individuals with cleft lip and palate: an overview. Indian J Plast Surg: Off. Publ. Assoc. Plast. Surg. India. 2009 Oct:42(Suppl):S137-S143.

6. Das VK. Aetiology of bilateral sensorineural hearing impairment in children: a 10 year study. Arch Dis Child. 1996 Jan 1;74(1):8-12.

7. Korver Anna MH, et al. Causes of permanent childhood hearing impairment. The Laryngoscope. 2011 Jan 26;121(2):409-416.

8. Censusindiagovin. Provisional population data sheet basic figures at a glance. http:// censusindia.gov.in/2011-prov-results/data files/lakshadweep/data\%20sheet.pdf.

9. Shanbal JC, Reddy MS. Distribution of communication disorders in primary school children. J. All India Inst. Speech Hear. 2015 Jan 1:128-133.

10. Konadath S, Suma C, Jayaram G, Sandeep M, Mahima G, Shreyank PS. Prevalence of communication disorder in rural population of India. J Hear Sci. 2013 Jun $1 ; 3(2): 41-49$.

11. Sinha SK, Shivaswamy J, Barman A, Seth D, Seshadri D, Savithri SR. Prevalence of communication disorders in a rural population at taluq level of Gujarat, India. Clin Epidemiol. Glob. Health. 2017 Jun 1;5(2):73-78.

12. Devadiga D, Varghese AL, Bhat J. Epidemiology of communication disorders and its role in rehabilitation. Int. J. Innov. Res. Dev. 2014 Dec 31;3(13):469-473.

13. World Health Organization. Grades of Hearing Impairment. http://www.who.int pbd/deafness/hearing_impairment_grades/en/index.html.

14. Belgaum K. reportDisability in Rural Population-A Community Based Cross Sectional Study (Doctoral dissertation, KLE University).

15. Shodhganga.inflibnet.ac.in/jspui/bitstream/10603/161608/11/11_chapter\%204. pdf.

16. Parvez A, Siddiui AR, Khan Z, Hasmi SF, Khan MS. Prevalence of hearing impairment among primary school children in rural and urban areas of Aligarh, Uttar Pradesh, India. Int. J. Community Med. Public Health. 2017 Feb 3;3(5):1273-1277.

17. Patil M, Handi P, Prasenkumar KR, Gouripur K. Objective screening of hearing impairment using brainstem evoked response audiometry in children below 5 years of age and assessing the high risk factors. Int. J. Otorhinolaryngol. Head Neck Surg. 2018;4(4):923. https://doi.org/10.18203/issn.2454-5929.ijohns20182475.

18. Bittles AH. The impact of consanguinity on the Indian population. Indian J Hum Genet. 2002;8(2):45-51.

19. Zakzouk S. Consanguinity and hearing impairment in developing countries: a custom to be discouraged. J Laryngol Otol. 2002 Oct;116(10):811-816.

20. Zakzouk S, El-Sayed Y, Bafaqeeh SA. Consanguinity and hereditary hearing impairment among Saudi population. Ann Saudi Med. 1993 Sep;13(5):447-450.

21. Singhi PD, Ray M, Suri G. Clinical spectrum of cerebral palsy in North India-an analysis of 1000 cases. J Trop Pediatr. 2002 Jun 1;48(3):162-166.

22. Sankar C, Mundkur N. Cerebral palsy-definition, classification, etiology and early diagnosis. Indian J Pediatr. 2005 Oct 1;72(10):865-868.

23. Gladstone M. A review of the incidence and prevalence, types and aetiology of childhood cerebral palsy in resource-poor settings. Ann. Trop. Paediatr. $2010 \mathrm{Sep}$ 1;30(3):181-196.

24. Armatas V. Mental retardation: definitions, etiology, epidemiology and diagnosis. $J$. Sport Heal. 2009;1(2):112-122. 